\title{
Negative Regulation of Platelet Activating Factor Signaling
}

National Cancer Institute

\section{Source}

National Cancer Institute. Negative Regulation of Platelet Activating Factor Signaling. NCI Thesaurus. Code C40604.

Any physiologic process which occurs in response to ligation of the platelet activating factor receptor, and results in a reduced number of active signaling molecules within the target cell. This process is involved in regulating the extent of platelet aggregation, inflammation and anaphylaxis. 